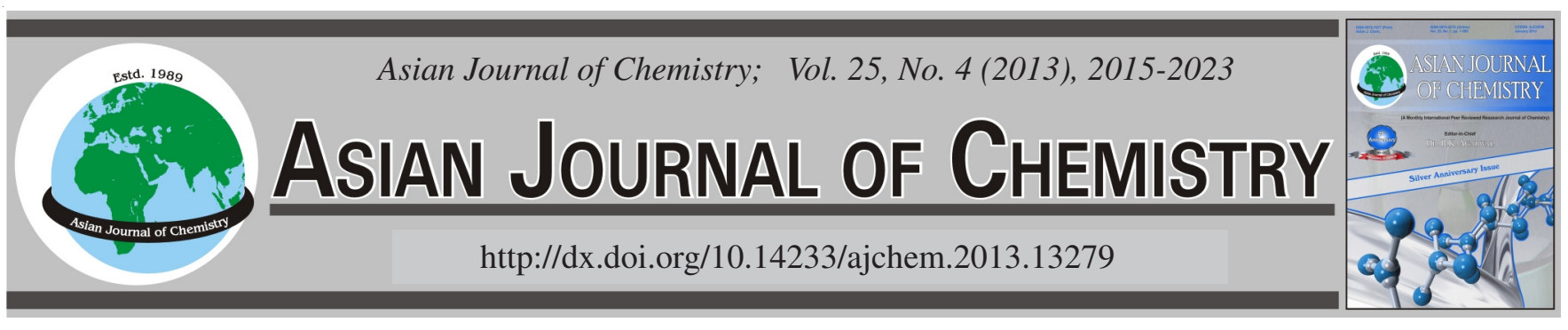

\title{
Effect of Environmental Conditions and Human Activities on Vertical Distribution Characteristics of Bacterial Communities in Shallow Lakes Sediments
}

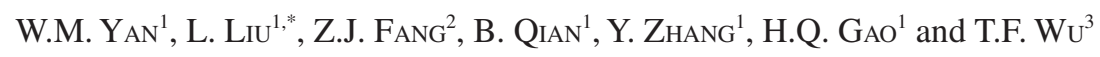

${ }^{1}$ State Key Laboratory of Hydrology-Water Resources and Hydraulic Engineering, Hohai University, Nanjing, P.R. China ${ }^{2}$ Guangdong Hydropower Design Institute, Guangzhou, P.R. China

${ }^{3}$ State Key Laboratory of Lake Science and Environment, Nanjing Institute of Geography and Limnology, Chinese Academy of Sciences, Nanjing, P.R. China

*Corresponding author: Fax: +86 25 83786606; Tel: +86 25 83786607; E-mail: lingliu2010620@ 163.com

\begin{abstract}
The aim of this study was to evaluate the microbial community structure in different sediment layers in the lakes such as Jiulongkou lake, Dazong lake and Wujindang lake located in Lixia river regions (regions between Liyunhe canal and Xiahe river) of the Huai river basin under the stress of nature and human activities. The diversity and dominance of bacterial community using the 16S rDNA cloningsequencing approach were determined within the appropriate sediment layers. Quantity software and UPGAMA cluster analysis were used to analyze the vertical distribution characteristics of bacterial community in combination with the related environmental data. The results show that there is an abundant diversity of bacteria in the lake sediments in Lixia river regions and there are differences in the abundance of longitudinal bacteria at different layers. The abundance of the middle layer is comparatively high, while the upper layer is lower and the lower layer is the lowest. Although there are some common clones in the sediments at different layers, the composition of predominant bacteria at different layers apparently varies. The experimental results show that the human activities have considerable impact on the environment of sediments in the downstream lakes and affect the bacterial community structure of sediments.
\end{abstract}

Key Words: Shallow lakes, Sediment, Bacterial communities, Vertical distribution.

\section{INTRODUCTION}

The microorganism in lakes sediments plays a key role in the degradation, conversion and energy flow of substances in the aquatic ecosystem and participates in the circulation of nutrient elements as well as the evolution and succession of lakes $^{1}$. The structure of microbial community is affected by multiple environmental factors and reflects changes in environment ${ }^{2}$. The research shows that the diversity of bacteria is related to the salinity, depth and nutritional types of lakes as well as specific season, etc. ${ }^{3,4}$. It has been discovered that the microbial content and number of active bacteria in the sediments are the highest at the surface layer and decrease with the increase in depth through research ${ }^{5,6}$. The depth affects the oxygen content and nutrient substance in the lake sediments with an indirect impact on the growth and population structure of bacteria. As shown by the research carried out by Sun $\mathrm{Jia}^{7}$ and Koizumi et al. ${ }^{6}$, the number and activity of bacterial are on the decrease with the increase in the depth of sediments. However, the research on sediments in lake Taihu carried out by Ye et al. ${ }^{8}$ shows that the content of all bacteria in the sediments increases with the increase in depth. The research on sediments of lake Taihu carried out by Zhao et al. ${ }^{9}$ confirmed that the diversity of bacteria fluctuates vertically. It has been discovered that changes in depth have no remarkable impact on the communities in sediments through the research on bacterial communities in the sediments of lake Taihu carried out by Zeng et al. ${ }^{10}$. The moisture content can affect the growth of bacterial by way of controlling the flow of water. For aerobic bacteria, a better growing environment is such an environment that water can be used more easily without fully saturated medium. The composition of grain size directly affects the transmission and distribution of organic matter as well as the level of water stagnating ability of soil, thus affecting the growth of bacteria. The research by Angela et al. ${ }^{11}$ shows that the distribution of grain size is an important factor affecting the bacterial communities. Work done by Kandeler et al..$^{12}$, reaches a conclusion that the number of bacteria per unit area is mainly decided by the content of clay particles. The pore space is small while the content of clay particles is large, thus affecting the activity of bacteria in the pore space. It has also been discovered that the distribution of bacteria is closely related to the size of particles in the bottom sediment through the research of bacteria in the bottom sediment in different waters carried out by Fleituch et al. ${ }^{13}$. The nutrient salt is an 
important material base for the growth of bacteria and its content directly affects the growth of bacteria ${ }^{14,15}$. It has been found that the content of bacteria in the bottom sediment is closely related to the physicochemical condition of bottom sediment through the research of Sander and Kalff ${ }^{16}$. The content of bacteria is significantly related to the total organic carbon, total nitrogen and total phosphorus in the sediments ${ }^{17}$. It can be seen from the existing research that the content of bacteria and population distribution in the lake sediments are related to multiple factors. The article will focus on the content of bacteria and distribution characteristics of population in the lake sediments under dual stress of natural factors and human activities.

The accurate determination of bacterial diversity and content is of great importance to the research of bacterial content and population distribution in the lake sediments ${ }^{18}$. The traditional method of bacterial culture can only detect very few bacteria in the environment, so it is difficult to represent the actual conditions in the microenvironment. The research means of molecular biology based on DNA fingerprint technique has overcome such disadvantages of the traditional method as long cycle, incomplete detection and low accuracy and widely used in recent years. For example, technologies like DGGE, T-RFLP, FISH, etc., have been introduced in the research of environmental bacteriology ${ }^{19-21}$. The research focuses on the evolution of sedimentary environment of lakes under the dual impact of nature and human activities, selects three lakes with different size and functions, Jiulongkou lake (JL), Dazong lake (DZ) and Wujindang lake (WJ) in Lixia river regions of the Huai river basin, as research areas, considers changes in depth as an entry point, makes use of PCR and DGGE technologies to study the microbial diversity of sediments at the surface layer of lakes and reveal its vertical distribution characteristics, provides a theoretical basis for treating the inner source pollution with regard to the eutrophication of lake as well as a material base for screening and developing the new functional genes of microorganism. Moreover, it is of great importance to understanding the circulation of substances and energy flow in the ecosystem of sediments.

\section{EXPERIMENTAL}

Sediment collection and preparation for field studies: In order to reveal the vertical distribution characteristics of bacterial communities in the lake sediments under the stress of nature and human activities, the research has selected 6 sampling points in $\mathrm{JL}, \mathrm{DZ}$ and $\mathrm{WJ}$ located in Lixia river regions in the middle and lower reaches of the Huai river (Fig. 1). Use of sediments -The collection of lake sediment sample was carried out from April 29, 2009 to May 2, 2009 by overlying a water column sampler. Under the premise of guaranteeing that the tube is filled with overlying water, sediments are separated on the site and layered by $1 \mathrm{~cm}$ at a depth of $0-5 \mathrm{~cm}$ and by $2 \mathrm{~cm}$ at a depth of more than $5 \mathrm{~cm}$, respectively. The layered samples are placed in the polyethylene bag and sealed and kept at $-20{ }^{\circ} \mathrm{C}$. Afterwards, it is carried back to the State Key Laboratory of Hydrology and Water Resources \& Water Conservancy Science and Engineering for DNA extraction, DGGE and PCR quantitative analysis.
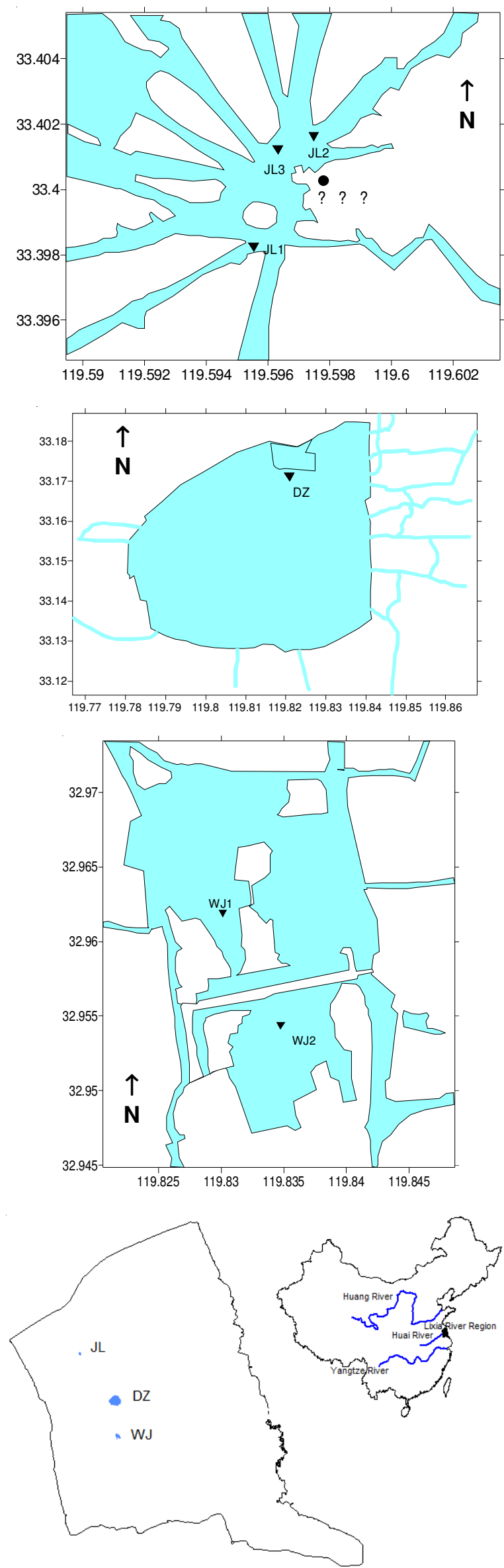

Fig. 1. Sketch map of the sampling site, Jiulongkou lake (JL), Dazong lake (DZ) and Wujindang lake (WJ), Jiangsu Province of China 
DNA extraction and purification and PCR amplification: Because the clay particle content of selected lake sediments is higher, up to 7.59-17.1\% and the high clay particle content can decrease the yield of SDS extraction method, thus, DNA extraction is carried out by the improved SDS method ${ }^{22}$ : bathe the sediments in water for $2 \mathrm{~h}$ at $65^{\circ} \mathrm{C}$ and slightly shake it every $15 \mathrm{~min}$ during this period and then freeze it at $-80^{\circ} \mathrm{C}$ for $10 \mathrm{~min}$ before bathing it in water bath for $10 \mathrm{~min}$ at $65^{\circ} \mathrm{C}$. Repeat the process three times. Other steps are the same as the SDS method. Roose-Amsaleg et al. ${ }^{23}$ viewed that this method is milder than the ultrasonic method and glass bead method and has higher extraction efficiency. DNA purification is carried out by the UNIK 10-column purification kit of Shanghai Sangon Biotech Co. Ltd.

The object of PCR amplification is 16S rDNA, the instrument is Rotor-Gene 6000 of American Bio-Rad and the primer is the universal primer F357/R518 of 16S rDNA V3 area synthesized by Shanghai Sangon Biotech Co. Ltd. ${ }^{24}$. The segment length of the amplified product is $c a .230 \mathrm{bp} .50 \mu \mathrm{L}$ system is applied: $1 \mu \mathrm{L}(10 \mu \mathrm{M})$ primer upstream and downstream respectively, 1 DNA template, $0.5 \mu \mathrm{L}$ Ex Taq ( $5 \mathrm{U} / \mu \mathrm{L})$ (TaKaRa, Japan), $5 \mu \mathrm{L} 10 \times$ buffer, $4 \mu \mathrm{L} \mathrm{MgCl}_{2}(25 \mathrm{mM})$ and $4 \mu \mathrm{L}$ DNTP (2.5 mM). PCR reaction conditions: PCR reaction uses touchdown fall PCR strategy ${ }^{24}$. RCR reaction product is detected by agarose gel electrophoresis of which the mass fraction is $1.5 \%$. The gel electrophoresis detection uses genetic mutation detection system of Dcode, Bio-Rad Corporation. The electrophoresis lasts for $16 \mathrm{~h}$ at constant voltage of $60 \mathrm{~V}$ and constant temperature of $60^{\circ} \mathrm{C}$. After the completion of electrophoresis, use $15 \mathrm{~mL} 1 \times$ SYBR Green I to dye for $0.5 \mathrm{~h}$ and Chemi Doc XRS TOTAL gel imaging system of Bio-Rad Corporation to take pictures.

Method for determining the bacterial content in sediments: Firstly, use type culture strain N. europaea ATCC 19718 to extract DNA as the template and amplify and purify, then cultivate to screen out recombinant plasmids to establish the standard curve reflecting the CT value and the copy number of environment samples. The equation is

$$
\mathrm{CT}=3.177 \times \log _{10}(\text { Crop })+36.315
$$

Crop is the initial copy number of PCR reaction system, copies/ $\mu \mathrm{L}$. CT: cycle threshold, expresses the cycle number which the fluorescence signals in each reaction tube undergo until having reached the set threshold value.

Add the extracted DNA into $25 \mu \mathrm{L}$ reaction system to have quantitative PCR reaction, the final concentration of upstream and downstream primer f1055/r1392 is 20 pmol, $1 \mu \mathrm{L}$ Taqman probe ${ }^{25}, 12.5 \mu \mathrm{L}$ Hot Star Taqman fluorescence quantitative PCR kit, $1 \mu \mathrm{L}$ DNA sample and finally use aseptic $\mathrm{ddH}_{2} \mathrm{O}$ to make up $25 \mu \mathrm{L}$; reaction conditions: pre-denaturation at $50{ }^{\circ} \mathrm{C} 3 \mathrm{~min}, 95^{\circ} \mathrm{C} 10 \mathrm{~min} ; 45$ circulations at $95^{\circ} \mathrm{C}$ $30 \mathrm{~s}, 50{ }^{\circ} \mathrm{C} 60 \mathrm{~s}$ and $72{ }^{\circ} \mathrm{C} 20 \mathrm{~s}$, with fluorescence available at $50{ }^{\circ} \mathrm{C}$ for each circulation. Get CT value of each environment sample and calculate the copy number of each environment sample according to the standard curve. Each cell contains 3.6 gene copies on average according to the gene cloning database $^{26}$. The formula is as follows:

$$
\mathrm{C}=\frac{\operatorname{cop} \times 25 \times \mathrm{V}_{1} \times \mathrm{V}_{2}}{\mathrm{~V}_{3} \times \mathrm{m} \times 3.6}
$$

where, $\mathrm{C}$ is bacterial content of the sample sediment (cells/g), cop is the initial copy number (copies/ $\mu \mathrm{L}$ ) obtained from PCR standard curve, $\mathrm{V}_{1}$ is the required volume of liquid $(\mathrm{mL})$ for dissolving DNA after purification, $\mathrm{V}_{2}$ is the volume of added buffer solution $(\mathrm{mL})$ to extract $\mathrm{DNA}, \mathrm{V}_{3}$ is the remaining volume $(\mathrm{mL})$ after coarse extraction of DNA and $\mathrm{m}$ is the dry weight (g) of sediments.

Methods of data processing and analysis: Electrophoretic bands are analyzed on the strength of Lane and Band functions in Quantity software. The quantity and density of electrophoretic bands reflect the diversity and uniformity of bacteria and the quantization of the Dice coefficient (CS) shows the similarity of different samples in DGGE map, i.e., bacterial communities change with its depth,

$$
\mathrm{CS}=\frac{2 \times \mathrm{j}}{\mathrm{a}+\mathrm{b}}
$$

$\mathrm{j}$ is the mutual DNA bands of the two samples, $\mathrm{a}$ and $\mathrm{b}$ are respectively unique bands of each sample. DGGE map can describe the distribution features of bacterial communities of sediments after UPGAMA cluster analysis.

Shannon-Weiner diversity index is comprehensive for studying the number of species and individuals, as well as distribution uniformity of communities ${ }^{25}$, which is used to show the relation between diversity of bacterial communities and numbers, strength and distribution of bands; Simpson index is used to reflect the dominance of species shown as formula (4-6).

$$
\begin{gathered}
\mathrm{H}^{\prime}=-\sum_{\mathrm{i}=1}^{\mathrm{S}}\left(\mathrm{P}_{\mathrm{i}} \ln \mathrm{P}_{\mathrm{i}}\right) \\
\mathrm{P}_{\mathrm{i}}=\frac{\mathrm{n}_{\mathrm{i}}}{\mathrm{N}} \\
\mathrm{D}=\sum_{\mathrm{i}=1}^{\mathrm{S}} \mathrm{P}_{\mathrm{i}}^{2}
\end{gathered}
$$

$\mathrm{H}^{\prime}$ : Shannon-Weiner diversity index, D: Simpson index, $\mathrm{S}$ is the total number of bands which can be recognized in each lane, $n_{i}$ is the gray level of the ith band and $\mathrm{N}$ is the total gray level of the lane.

\section{RESULTS AND DISCUSSION}

Evolution features of characteristic bands of samples at each layer of lake sediments: This study reflects the diversity and uniform of bacteria with the quantity and density of eletrophoretic bands, shows the similarity among different samples with Dice coefficient and describes distribution features of bacterial communities of sediments with cluster analysis.

The maximum and minimum of the three sediment column bands of JL are basically similar, the band numbers rise and fall with the depth but without regularity and the extreme value appears at different depths [Fig. 2(a-c)]. Thus, with the variation of sediment depth, there are both increase and extinction of characteristic bands (species) of sediments in JL. In JL1, species represented by characteristic bands of 25, 26, 1-33 and 41-43 appear in the whole sediment column and are 


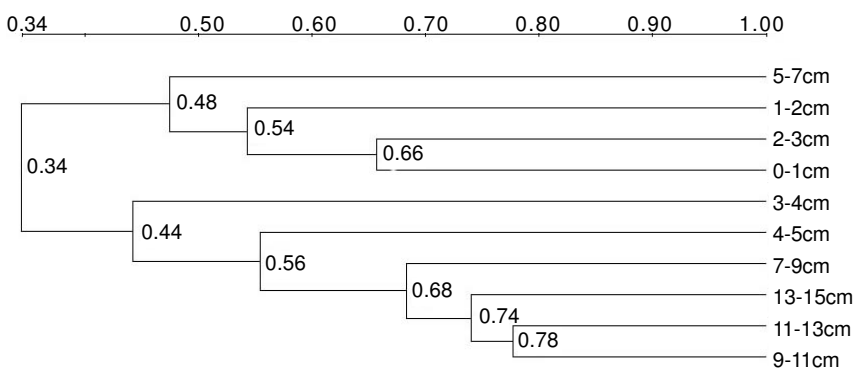

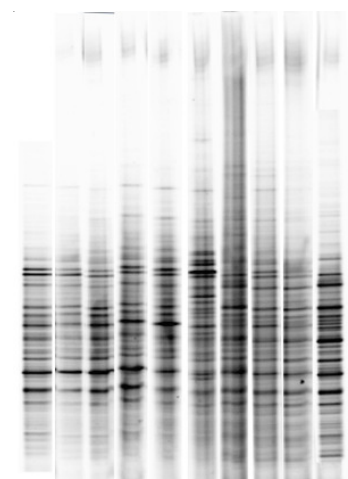

(a) JL1 Depth of DGGE bands from left to right is $0-1 \mathrm{~cm}, 1-2 \mathrm{~cm}, 2-3$ $\mathrm{cm}, 3-4 \mathrm{~cm}, 4-5 \mathrm{~cm}, 5-7 \mathrm{~cm}, 7-9 \mathrm{~cm}, 9-11 \mathrm{~cm}, 11-13 \mathrm{~cm}, 13-15 \mathrm{~cm}$
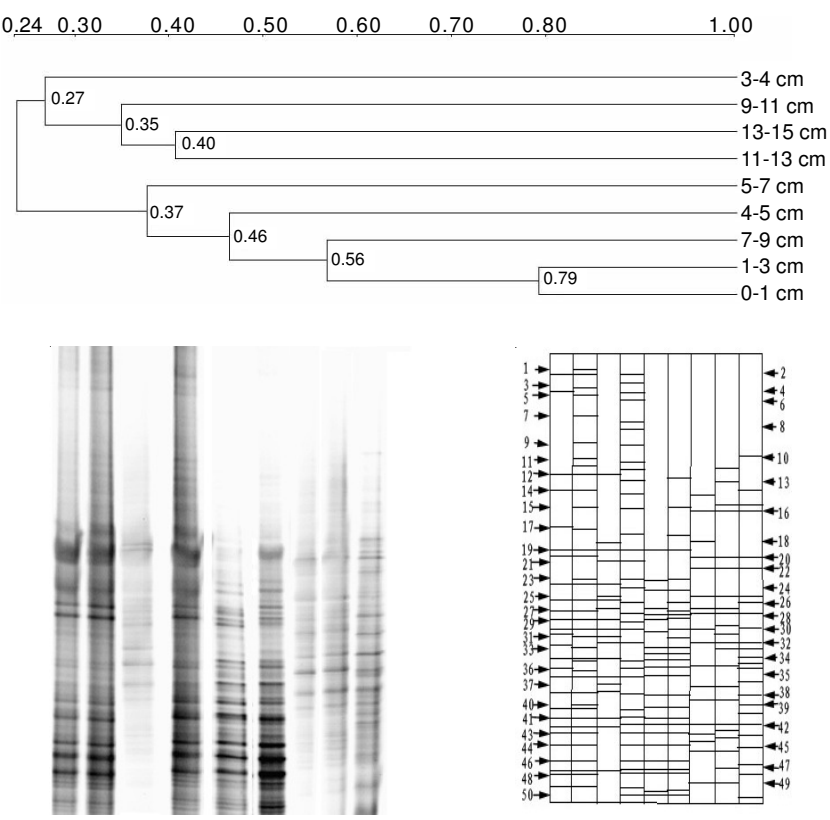

(b) JL2 D Depth of DGGE bands from left to right is 0-1 cm, 1-3 cm, 3-4 $\mathrm{cm}, 4-5 \mathrm{~cm}, 5-7 \mathrm{~cm}, 7-9 \mathrm{~cm}, 9-11 \mathrm{~cm}, 11-13 \mathrm{~cm}, 13-15 \mathrm{~cm}$

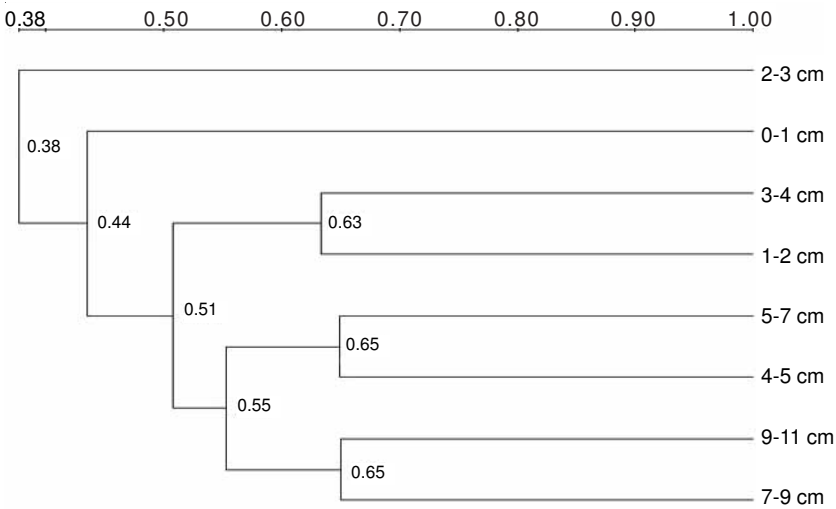

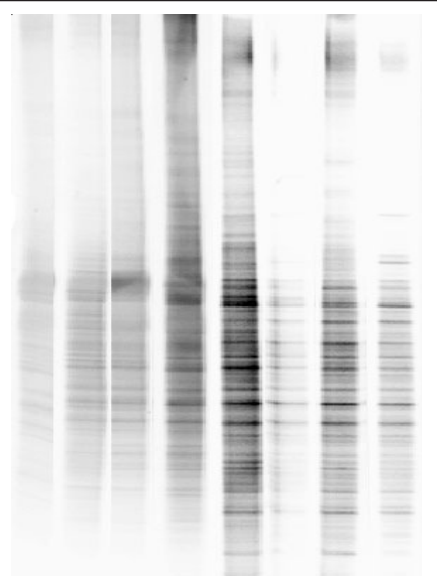

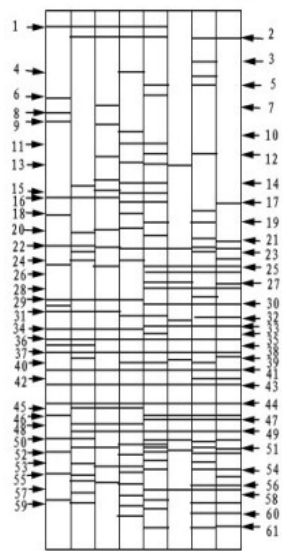

(c) JL3 Depth of DGGE bands from left to right is $0-1 \mathrm{~cm}, 1-2 \mathrm{~cm}, 2-3 \mathrm{~cm}$ $3-4 \mathrm{~cm} \mathrm{4-5} \mathrm{cm} \mathrm{5-7} \mathrm{cm} \mathrm{7-9} \mathrm{cm} \mathrm{9-11} \mathrm{cm}$
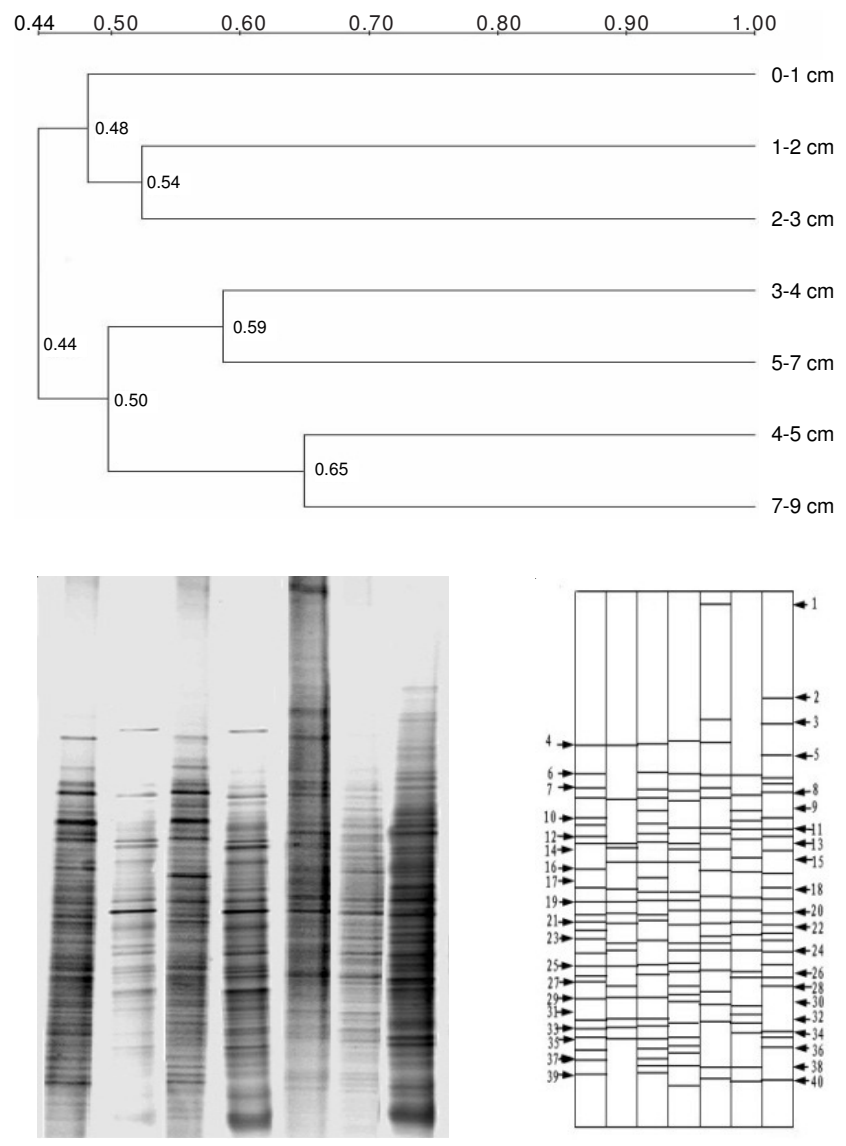

(d) DZ Depth of DGGE bands from left to right is 7-9 cm, $5-7 \mathrm{~cm}, 4-5 \mathrm{~cm}$, $3-4 \mathrm{~cm}, 2-3 \mathrm{~cm}, 1-2 \mathrm{~cm}, 0-1 \mathrm{~cm}$

$\begin{array}{lllllll}0.44 & 0.50 & 0.60 & 0.70 & 0.80 & 0.90 & 1.00\end{array}$

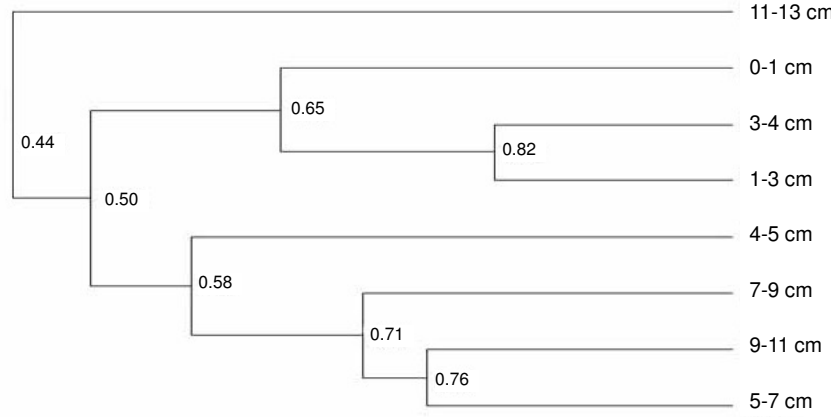



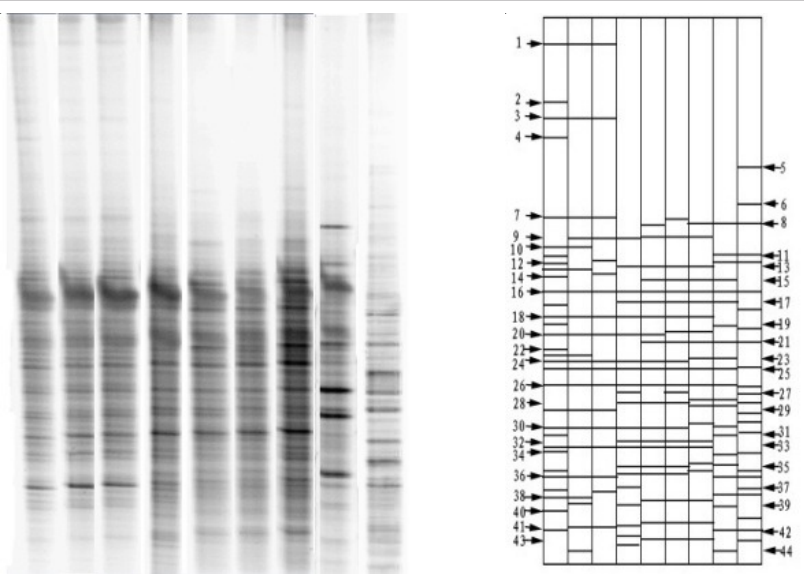

(e) WJ1 Depth of DGGE bands from left to right is $0-1 \mathrm{~cm}, 1-3 \mathrm{~cm}, 3-4$ $\mathrm{cm}, 4-5 \mathrm{~cm}, 5-7 \mathrm{~cm}, 7-9 \mathrm{~cm}, 9-11 \mathrm{~cm}, 11-13 \mathrm{~cm}$, marker
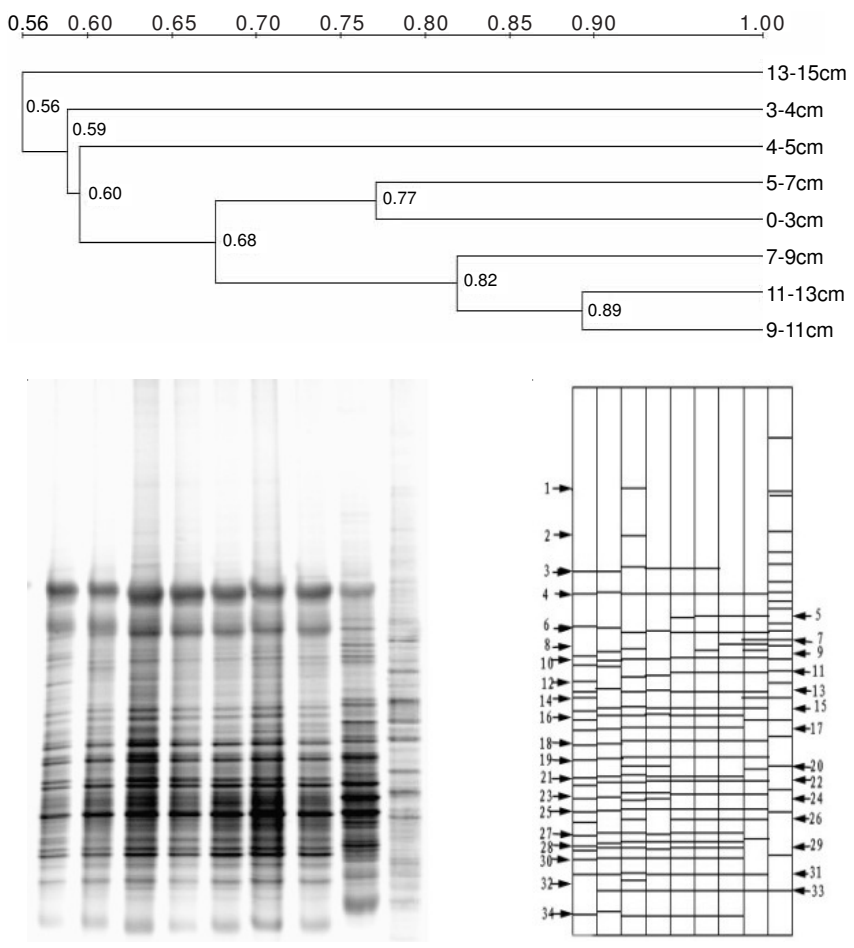

(f) WJ2 Depth of DGGE bands from left to right is $0-3 \mathrm{~cm}, 3-4 \mathrm{~cm}, 4-5$ $\mathrm{cm}, 5-7 \mathrm{~cm}, 7-9 \mathrm{~cm}, 9-11 \mathrm{~cm}, 11-13 \mathrm{~cm}, 13-15 \mathrm{~cm}$, marker

Fig. 2. Clustering analysis, DGGE diagrams and DGGE bands of bacterial communities in shallow lakes sediments

dominant species at different depths; species represented by Band 1-12 only appear when the sedimentation depth is over $2 \mathrm{~cm}$; while species represented by Band 14 and Band 24 gradually extinct when the depth is more than $9 \mathrm{~cm}$. In JL2, species represented by characteristic bands of 28, 42 and 43 appear in the whole sediment column and are dominant species at different depths; species represented by Band 1-9 only appear in the sediment of 0-5 cm depth; species represented by Band 16, 22 and 25 only appear in the sediment of more than $9 \mathrm{~cm}$ depth. In JL3, species represented by Band 22, 36, $37,41,43$ and 44 are dominant bands at a depth of $0-11 \mathrm{~cm}$; species represented by Band 1, 16 and 29 gradually extinct when the sedimentation depth is more than $5 \mathrm{~cm}$; species represented by Band 26, 28, 30, 47 and 57 only appear when the sedimentation depth is more than $5 \mathrm{~cm}$.
The three sediment columns of JL are clustered based on the sedimentation depth on the whole. According to the similarity of biological communities reflected by Dice coefficient, JL1 can be gathered into 3 classes: sediments of 0-3 and 5-7 $\mathrm{cm}$ are Class A, 4-5 and 7-15 $\mathrm{cm}$ are Class B and 3-4 $\mathrm{cm}$ are Class C; the similarity of biological communities of 9-11 and $11-13 \mathrm{~cm}$ is the highest with the Dice coefficient of 0.78 , while the similarity of Class A and Class $\mathrm{C}$ is the lowest with the Dice coefficient of 0.34 only. JL2 can also be gathered into 3 classes. Class A is sediments of 0-3 and 4-9 cm, Class B for 9-15cm and Class $\mathrm{C}$ for $3-4 \mathrm{~cm}$, among which the highest similarity of bacteria appears in the sediments of 0-1 and 1-3 $\mathrm{cm}$ at different depths, with the Dice coefficient of 0.79 , while the similarity of Class A and Class $\mathrm{C}$ is the lowest with the Dice coefficient of 0.24 . JL3 also has three classes. Class A is sediments of 1-2 and 3-11 cm, Class B for 0-1 cm and Class C for 2-3 cm, among which the similarity between 4-5 and 5-7 $\mathrm{cm}$ and between $7-9$ and $9-11 \mathrm{~cm}$ is the highest with the Dice coefficient of 0.65 , while the similarity between Class $\mathrm{C}$ and Class A is the lowest with DC 0.38 only.

Bands (species) rise first and then fall with the depth of sediment at the $0-9 \mathrm{~cm}$ of DZ; at $5-7 \mathrm{~cm}$, the minimal value of bands appears; at other depths, the bands of sediments slightly varied [Fig. 2(d)]. It shows that the species of bacterium in 0-9 cm sediments of DZ is of uniform distribution. Characteristic bands (species) of DZ sediments varied with their sedimentation depth. Species represented by characteristic bands 8, 21 and 22 are dominant species in 0-9 cm sediments, species represented by bands $1-3,5,18,31$ and 34 only appear in 0-3 sediments, while species represented by bands 4 and 33 gradually appear at a sedimentation depth of over $3 \mathrm{~cm}$. The sediments at different depths in DZ can be classified into 2 classes, among which 0-3 cm is Class A and 3-9 cm is Class B. The similarity of neighboring layers is low with DC 0.44 ; while the similarity of $4-5$ and $7-9 \mathrm{~cm}$ is the highest with DC 0.65 .

Bands of sediment columns in WJ change a little with the depth and the maximum and minimum of two bands of sediment columns are similar [Fig. 2(e-f)]. Number of bands of WJ1 is maximum when the depth is $0-1 \mathrm{~cm}$ and it basically remains invariable when the depth is more than $1 \mathrm{~cm}$; band number of WJ2 first increases and then decreases, the maximum appears when the depth is $4-5 \mathrm{~cm}$ and the band number fluctuates within a small scale when the depth is more than $5 \mathrm{~cm}$. In general, the quantities of bacterial species of the two sediments of WJ do not change a lot with the depth. In WJ1, Band 16, 18, 24, 25, 30, 34, 36 and 41 represent dominant species, Band 8, 17, 21 and 39 appear only when the depth is more than $5 \mathrm{~cm}$. In WJ2, bacterial species of sediment do not change obviously with the sedimentation depth when they are 0-5 cm deep and most species appear at different sedimentation depths. For example, species represented by Band 4, 6 , $10,13,17-23,25$ and 27-31 exist in sediments at a depth of $0-15 \mathrm{~cm}$ and are dominant species. However, some bands appear only at a special depth. For example, species represented by Band 1, 2 and 3 exist only in sediments at a depth of 4-5 $\mathrm{cm}$, while species represented by Band 3 and Band 5 exist in sediments at a depth of $0-11 \mathrm{~cm}$. WJ1 sediments can be divided 
into 3 classes based on Dice coefficient, among which $0-4 \mathrm{~cm}$ sediments belong to Class A, 4-11 cm are Class B and 11-13 $\mathrm{cm}$ are Class $\mathrm{C}$; the highest similarity of bacterial communities is between 1-3 cm sediments and 3-4 cm sediments with the Dice coefficient of 0.82 , while Class B and Class $\mathrm{C}$ have the lowest similarity whose Dice coefficient is only 0.44 . WJ2 can be divided into 4 groups, among which $0-3 \mathrm{~cm}$ and 5-13 $\mathrm{cm}$ sediments belong to Class A, 4-5 cm are Class B, 3-4 cm are Class $\mathrm{C}$ and $13-15 \mathrm{~cm}$ are D class. The highest similarity of bacteria in different depths appears in 9-11 and 11-13 cm sediments with the Dice coefficient of 0.89 , while the lowest similarity is between Class D and Class C with the Dice coefficient of 0.56 only.

Results of cluster analysis demonstrate that there is no significant difference between bacteria species compositions at different depths of lake sediments. Bacteria communities of JL1 and JL2 sediment columns takes a certain depth as its dividing point, with considerable difference between the upper and lower layers; JL3 changes slightly in its vertical direction. Composition of bacteria communities in sediments at different depths indicates that JL1 and JL2 are greatly similar; bacteria of these two sediment columns at a depth of 3-4 cm are greatly different from the upper and the lower sediments, with unique characteristics. Clustering method of JL3 sediments is obviously different from JL1 and JL2 sediment columns, which may be attributable to strong scour incurred by JL1 and JL2 due to their location on the lake outlet. DZ sediment sample community can be classified according to depth and its critical depth is $3 \mathrm{~cm}$ which is just the critical depth of AAP content in sediments changing from high to low value. Sediment columns in DZ are classified as per depth and its critical depth is $3 \mathrm{~cm}$ on both sides of which there is little similarity. Change pattern of WJ1 bacterial community composition with the change of depth is more obviously observed than WJ2, which may be attributable to the flourish aquatic plants in $\mathrm{WJ} 1$ sampling point, surface layer full of nutriments and deep layer lack of nutriments. Variation of bacterial community composition in WJ1 sediment with the change of depth takes $4 \mathrm{~cm}$ as it dividing point on both sides of which bacterial community composition is sharply different while changes of $\mathrm{WJ} 2$ are not obvious, which is identical with the vertical distribution characteristics of AAP content. AAP with higher bioactivity can be easily converted to soluble phosphates. PAOs is capable of storing phosphorus in the form of condensed phosphate in cells to affect bacteria growth so as to influence bacterial community composition.

Vertical distribution of diversity and dominance of sediment bacteria: Fig. 3 showed the vertical changes of Shannon-Weiner and Simpson index of sediment bacteria of the three typical lakes. There are varieties of sediment bacteria in JL and its maximum and minimum, respectively appear in 1-2 $\mathrm{cm}$ sediments and 9-11 cm sediments. Shannon-Weiner index of JL2 and JL3 sediment bacteria fluctuate with the depth, while JL1 fluctuates at 0-5 cm. The average ShannonWeiner indexes of the three sediment columns are similar and slightly different at the same depth. The Shannon-Weiner index of bacteria of the two sediment columns in WJ fluctuates in a vertical direction and is a bit lower than the sediment of JL. The bacterial Shannon-Weiner index of sediment in DZ is
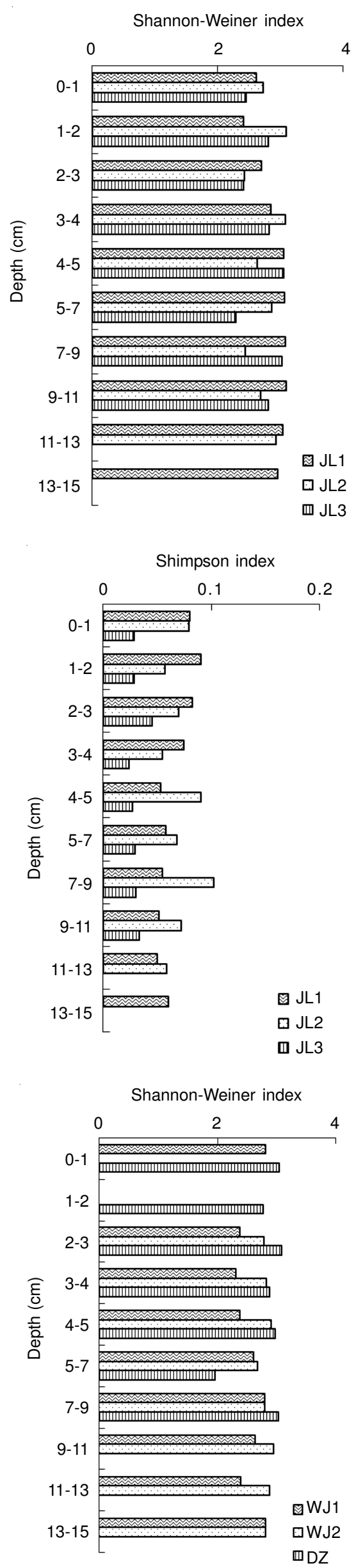


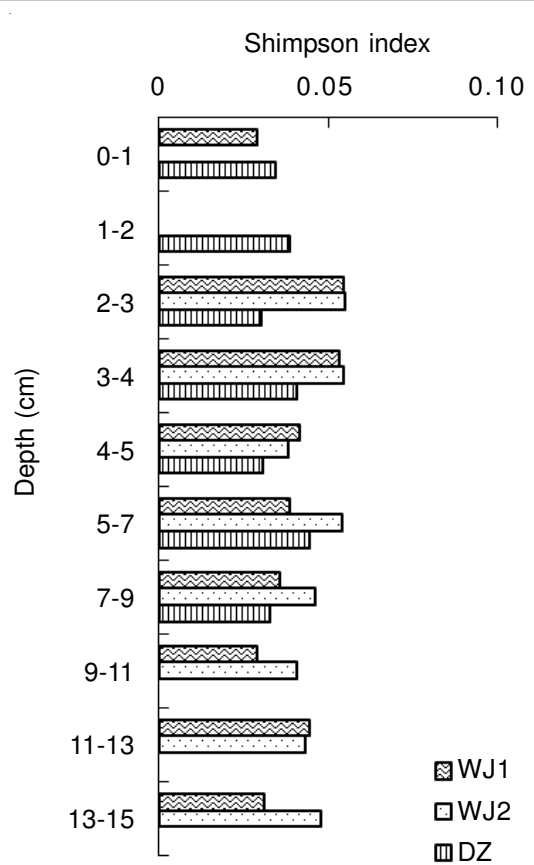

Fig. 3. Vertical distribution characteristics of bacterial Shannon-Weiner index and Simpson index in shallow lakes sediments

similar to the other two lakes, but its minimum appears in the sediment at a depth of 5-7 cm.

The Simpson index of JL3 sediment column is much lower than JL1 and JL2, which shows that dominant species in sediment bacteria of JL1 and JL2 are more than those of JL3. The Simpson index of JL1 fluctuates when the depth is 0-5 $\mathrm{cm}$ and its vertical variation trend of $5 \mathrm{~cm}$ deep is the same as Shannon-Weiner. JL3 fluctuates in the vertical direction. The Simpson index of DZ bacteria is a little bit higher than JL3 but lower than other sediment columns. The sediment bacteria distribute uniformly in the vertical direction. The bacterial Simpson index of WJ1 sediment column is a little bit lower than that of $\mathrm{WJ} 2$, which shows that there are more dominant species in WJ2, since WJ2 seldom connects with other surface water and it is an aquatic culture zone. The Simpson index of 3-11 cm deep sediment of WJ1 decreases with the increase of depth and the increasing point suddenly appears in the 11-13 $\mathrm{cm}$ sediment. WJ2 sediment column fluctuates in the vertical direction.

Shannon-Weiner index and Simpson index among different lakes vary markedly. There is an abundant variety of bacteria in the three typical lakes, where Shannon-Weiner and Simpson indexes fluctuate in the vertical direction, as a possible consequence of the combined action of multiple factors. The study on Lake Taihu by Zhao et al. ${ }^{9}$ also produces the same result. Bacterial community composition at different sedimentation depths of typical lakes has no obvious difference. Moreover, the diversity index, Simpson index and content of bacteria in sediments have different distribution features in the vertical direction.

Vertical distribution characteristics of bacterial content in sediments: Fig. 4 showed the vertical distribution of the overall bacterial content in sediment columns in three typical lakes. Three sediment columns in JL have the similar vertical distribution characteristics, but their overall bacterial
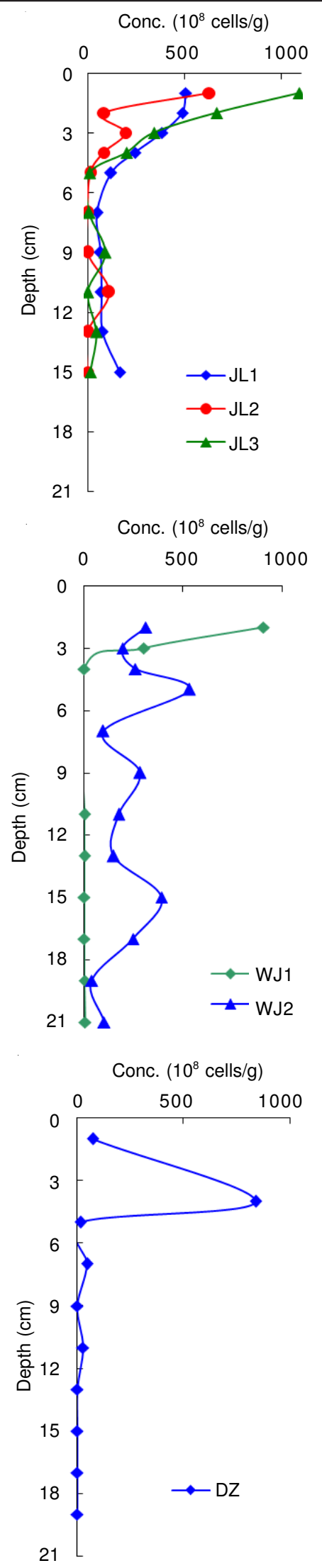

Fig. 4. Vertical distribution characteristics of bacterial communities in shallow lakes sediment

content is largely different from each other with the size relationship of JL3 $>$ JL1 $>$ JL2 and the size relationship of maximum bacterial content of JL3 $>$ JL2 $>$ JL1 three sediment 
columns in JL have the similar vertical distribution characteristics, but their overall bacterial content is largely different from each other with the size relationship of JL3 > JL1 > JL2 and the size relationship of maximum bacterial content of JL3 $>$ JL2 > JL1. Bacterial content falls as depth increases (Fig. 4). It presents a sharp decrease at a depth of $0-7 \mathrm{~cm}$ and yet makes little change at a depth of $7-15 \mathrm{~cm}$. Total bacterial content of WJ1 is totally different from that of WJ2 in the tendency of vertical changes. The former drops sharply at a depth of 0-4 $\mathrm{cm}$ and basically remains the same at a depth of more than $4 \mathrm{~cm}$, which is similar to sediments of JL. However, the latter presents a waveform change and greatly varies at different depths. The maximum value appears at $4-5 \mathrm{~cm}$ and the minimum value exists at $17-19 \mathrm{~cm}$. At a depth of over $3 \mathrm{~cm}$, the overall bacterial content of WJ2 sediments is bigger than that of WJ1 when nutrients provided by surface-layer aquatic plants decrease. Bacterial content of DZ sediments changes a little with the depth. Compared with bacteria on the surface layer, bacteria on the deep layer decrease slightly. Except that a skyrocketing extreme point appears at a depth of $4 \mathrm{~cm}$, bacterial content sharply decreases downwards and is stabilized along with the increase of depth.

Detection results of bacterial content in sediments indicate that the total quantity of bacteria in sediments at a depth of $0-5 \mathrm{~m}$ is rich, up to 201-462108 cells/g; it drops as the depth exceeds $5 \mathrm{~cm}$, reducing to dozens of 108 cells/g. Variation of bacterial content in vertical direction tends to decrease as the depth increases and the overall bacterial content of sediment columns in different lakes is markedly different from each other. At a depth of $0-3 \mathrm{~cm}$, the overall bacterial content of JL, JL2, JL3 and WJ1 sediments is higher than that of DZ and $\mathrm{WJ} 2$. One of the reasons for it is that emergent aquatic plants in JL1, JL2, JL3 and WJ1 sampling points are flourishing and the root systems in the surface sediment are numerous. Root system is beneficial for bacterial enrichment and reproduction, thus increasing the bacterial content to a higher extent in surface sediments, while, the impact of the root system of aquatic plants is basically eliminated as sedimentary depth increases. Another reason is that content of NAIP, OP and BAP with higher bioactivity in JL1, JL2, JL3 and WJ1 sediments is higher, which provides abundant phosphorus nutrition for bacteria growth. Higher bacteria bioactivity helps restore $\mathrm{Fe}^{3+}$ to $\mathrm{Fe}^{2+}$ and promotes NAIP release in sediments ${ }^{27}$. The overall bacterial content of DZ is lower than other sampling points, which may be attributable to Lake Taihu's past dredging. At a depth of $0-3 \mathrm{~cm}$, the overall bacterial content of WJ1 is larger than WJ2, which may be explained as follows: flourishing aquatic plants in $\mathrm{WJ} 1$ provide abundant nutrition for bacteria in sediments to guarantee bacteria reproduction and growth and root system is more beneficial for bacteria enrichment and reproduction ${ }^{28}$. Bacterial content at different depths of WJ2 varies greatly, which may be attributable to quite unsteady vertical distribution of physicochemical properties of WJ2 sediment columns, which directly affects the growth of bacteria In all sediment columns, bacterial content in the vertical direction tends to decrease as the depth increases, which is identical with results of $\operatorname{Sun}^{7}$ and Koizumi et al. ${ }^{6}$. The aforementioned discussion gives further proof that bacterial content and distribution in sediments are closely related to nutrition content and distribution.

\section{Conclusion}

The bacterial community composition of sediments among regions is more significant different than that among depths. The concentration of bacteria is rich and diversity of bacteria is high in sediments of the study area and the sediments of heavy phosphorus-polluted are rich in bacteria than the others. From the vertical, the vertical distribution of bacterial concentration in sediments of JL and WJ1 is significant different to that of DZ and WJ2. In a word, sedimentary environment of these lakes chosen by our institution is susceptible to the re-suspension caused by external forces such as wind, sailing, fishing and external force. Similarity analysis of bacterial distribution, content and community shows that bacterial content on the upper layer of these three lakes is greatly larger than that of the lower layer. The reasons are as follows: in recent years, lake sediment suffers from increasingly severe pollution and eutrophication due to economic development, purse seine breeding and tourism development. JL as a swamp tourism lake is susceptible to tourism; DZ as a breeding lake is susceptible to fishing industry; WJ as an urban breeding lake is susceptible to domestic sewage and fishing industry.

As shown by clustering results of bacteria communities, lake sediment takes a certain depth as its dividing point and similarity between upper and lower bacteria communities is slight. In dredging lake sediments, it is necessary to carefully take into account the depth of dredging, or it may destroy the microorganism system and ecological structure in sediments. For example, some nitrobacteria and ammonia oxidizing bacteria with decomposition function may be cleared out, consequently reducing water quality purification effect and destroying the balance of aquatic ecosystem. Dredging in areas where similarity between bacteria communities is higher and bacterial content slightly changes with the increase of depth causes less damage to microorganism system in the sediment, such as WJ2 point, Therefore, intensive study on bacterial community distribution characteristics in the sediments can provide an information basis for understanding lake pollution history in Lixia river regions of the Huai river basin and lake control.

\section{ACKNOWLEDGEMENTS}

The authors thank to our colleagues L.N. Xu, X.L. Yao, F. Yan, L.Y. Chen, Q. Xia and L.T. Wang for their laboratory and field assistanceship. This study was supported by the National Natural Science Foundation of China (50879018, 41101458), Graduate Student Scientific Research Innovation Plan of Jiangsu Province (CXZZ11_0436).

\section{REFERENCES}

1. G. Szabo, B. Khayer, A. Rusznyak, T. Stvan, G. Devai, K. Marialigeti and K.B. Andrea, Hydrobiologia, 663, 217 (2011).

2. E. D'Angelo and A. Nunez, J. Soils Sediments, 10, 1186, (2010).

3. H.Y. Dang, R.P. Chen, L. Wang, L.Z. Guo, P.P. Chen, Z.W. Tang, F. Tian, S.Z. Li and G.K. Martin, AEM, 11, 7036 (2010).

4. Q.L. Wu, G. Zwart and M. Schauer, Appl. Environ. Microbiol., 72, 5478 (2006).

5. F.M. Blondin, G. Nogaro and T. Dally, Environ. Pollut., 138, 57 (2005).

6. Y. Koizumi, H. Kojima and M. Fukui, FEMS Microbiol. Ecol., 44, 101 (2003). 
7. J. Sun, Third Institute of Oceanography, State Oceanic Adiministration, Master's Degree Dissertation, P.R. China (2008).

8. W.J. Ye, X.L. Liu and S.Q. Lin, FEMS Microbiol. Ecol., 70, 263 (2009).

9. X.Q. Zhao, L.Y. Yang and D.Q. Yin, Environ. Sci., 29, 3537 (2008).

10. J. Zeng, L.Y. Yang and J.Y. Li, World J. Microbiol. Biotechnol., 25, 225 (2009).

11. S. Angela, W. Alexandra and H.G. Martin, Appl. Environ. Microbiol., 9, 4215 (2001)

12. E. Kandeler, D. Tscherko and Bruce, Biol. Fert. Soils, 32, 390 (2000).

13. T. Fleituch, A. Starzecka and T. Bednarz, Hydrobiologia, 464, 165 (2001).

14. Y.H. Xu, X. Jiang and X.C. Jin, Environ. Sci., 27, 869 (2006).

15. M. Hupfer, R. Gachter and H. Ruegger, Limnol. Oceanogr-Methods, 40, 610 (1995).

16. B.C. Sander and J. Kalff, Micro. Ecol., 26, 79 (1993).

17. F. Feng, Master's Degree Dissertation, Hydrobiology, the Chinese Academy of Sciences Wuhan Hubei, P.R. China (2006).

18. G.H. Wang, J. Dong, X. Li and H.M. Sun, Acta Oceanol. Sin., 29, 98 (2010)
19. J.F. Salles, F.A. De Souza and J.D. Elsas, Appl. Environ. Microbiol., 68, 1595 (2002).

20. J.F. Salles, J.D. Elsas and J.A. Veen, Microbiol. Ecol., 52, 267 (2006).

21. M.D. Kane, L.K. Poulsen and D.A. Stahl, Appl. Environ. Microbiol., 3, 682 (1993)

22. J. Zhou, A. Brunsm and J.M. Tiedje, Appl. Environ. Microbiol., 62, 316 (1996)

23. C.L. Roose-Amsaleg, E.G. Sillam and M. Harry, Appl. Soil Ecol., 18, 47 (2001).

24. D.A. Stahl and W. Capman, NATO ASI Series G, 35, 193 (1994).

25. L. Tawan, S. Yuko and K. Futoshi, FEMS Microbiol. Ecol., 54, 205 (2005).

26. P. Xing, F.X. Kong and G. Gao, J. Lake Sci., 19, 373 (2007).

27. X.H. Sun, Y. Zhang and B.L. Zhang, Environ. Chem., 1, 24 (2006).

28. H. Zhang, G.R. Chen and Z.B. Wu, J. Central China Normal Univ. (Nat. Sci.), 33, 575 (1999). 